\title{
Nimotuzumab in Management of Brain Stem Glioma: A Case Report
}

\author{
K. S. Kirushna Kumar*, P. Ananda Selvakumar, Krishna Kumar Rathinam \\ Meenakshi Hospital and Research Centre, Madurai, India \\ Email:^drkskk@yahoo.com
}

How to cite this paper: Kumar, K.S.K., Selvakumar, P.A. and Rathinam, K.K. (2017) Nimotuzumab in Management of Brain Stem Glioma: A Case Report. Journal of Cancer Therapy, 8, 216-224.

https://doi.org/10.4236/jct.2017.82018

Received: November 8, 2016

Accepted: February 21, 2017

Published: February 24, 2017

Copyright $\odot 2017$ by authors and Scientific Research Publishing Inc. This work is licensed under the Creative Commons Attribution International License (CC BY 4.0).

http://creativecommons.org/licenses/by/4.0/

(c) (i) Open Access

\begin{abstract}
Brainstem glioma is rare tumour in adults accounting for $1 \%-2 \%$ of intracranial gliomas. In this case study, a 28-year-old female diagnosed with BG, and lesions were observed in the pons and medulla region of the brain stem. She was initially treated with radiotherapy (54 Gy in 30 fractions for 6 weeks) but no change in her clinical condition and size of tumor was observed. Temozolomide ( $250 \mathrm{mg} /$ daily for 5 days) was prescribed as first line chemotherapy. After completion of three cycles of Temozolomide, patient presented with diplopia and MRI showed increase in the size of lesions. After unsatisfactory response to radiation and chemotherapy, the patient was treated with Nimotuzumab therapy. MRI scan demonstrated the reduction of lesion size after 8 cycles of Nimotuzumab ( $200 \mathrm{mg} /$ week). This treatment continued for another 8 cycles and the MRI scan of patients showed a significant reduction in lesion size. Nimotuzumab was found to be an effective and safe treatment option for brainstem glioma patient who was resistant to radiotherapy and chemotherapy.
\end{abstract}

\section{Keywords}

Brainstem Glioma, Epidermal Growth Factor Receptor (EGFR), Nimotuzumab

\section{Introduction}

Brainstem glioma (BG) occurs in the midbrain, the pons, or the medulla oblongata and is uncommon in adults, accounting for only $1 \%-2 \%$ of intracranial gliomas. Magnetic resonance imaging (MRI) is widely used tool for diagnosis of brainstem glioma as biopsies are rarely performed in brainstem tumours [1]. Mainstay of management for malignant glioma has been surgery, radiotherapy (RT) trailed by alkylating agents such as the nitrosoureas, procarbazine, and, temozolomide. Novel pharmacotherapies are developed in an effort to target 
specific molecular mechanisms involved in abnormal signalling and to overcome resistance of traditional chemotherapy drugs, such as temozolomide (TMZ). Despite significant advances in neuroradiology techniques, there is an unmet medical need for the treatment of BG.

Resistance to therapy is the main hindrance of poor patient outcomes [2]. TMZ is an alkylating agent prodrug, producing its cytotoxic activity by the formation of O6-methylguanine DNA (O6-guanine; N7-guanine and N3-adenine). This primary cytotoxic lesion, O6-methylguanine can be removed by methylguanine methyltransferase (MGMT) in tumours expressing this protein, or tolerated in mismatch repair-deficient (MMR) tumours. Thus MGMT or MMR deficiency reflects resistance to temozolomide [3].

Conventional radiotherapy is the standard treatment for diffuse intrinsic low-grade brainstem gliomas in adults (the median survival is 5 years) [4]. Usually all brainstem gliomas respond to radiotherapy as decided by the mitigation of neurological symptoms and evidence for improved duration of survival in patients given higher doses ( $>50 \mathrm{~Gy} \mathrm{v}<50 \mathrm{~Gy}$ ) of radiotherapy. However, the potential advantage of combination treatment of radiotherapy and chemotherapy is not entirely evaluated in adult patients [1].

Targeted therapies are the next revolution in the management of brainstem glioma. Nimotuzumab is a humanized monoclonal antibody against epidermal growth factor receptor (EGFR) approved for the squamous cell carcinoma of head and neck (SCCHN) in India. It has been given an orphan drug status for glioma in USA and for glioma and pancreatic cancer in Europe [5].

\section{Case Presentation}

\subsection{Investigations}

A female of 28 years old apparently healthy was visited our hospital on 10th December 2013. She complained the symptoms such as a progressive headache, nausea, and vomiting. Her body weight was recorded as $56 \mathrm{~kg}$ and height 162 $\mathrm{cm}$. A MRI scan was done on 11th December 2013 and identified the presence of an expansile lesion in the pons, medulla and cervico-medullary junction with extension into the middle and inferior cerebellar peduncle on left side (Figure 1). Patient had elevated levels of choline and reduced levels of $\mathrm{N}$-acetyl aspartate, creatine, $\mathrm{N}$-acetyl aspartate and choline ratio ( $\mathrm{Naa} / \mathrm{Cho})$ and mild amino acid peak. She was diagnosed with brainstem glioma.

\subsection{Treatments}

The first treatment was initiated on $13^{\text {th }}$ December 2013 with 3-Dimensional Conformal Radiotherapy (3DCRT). The patient was given External Beam Radiotherapy (EBRT) $54 \mathrm{~Gy}$ in 30 fractions for 6 weeks. Radiotherapy was completed on $2^{\text {nd }}$ February 2014. Radiotherapy did not show any improvement in clinical condition/symptoms of the patient. Patient was further assessed with MRI scan 6-week post radiotherapy on $18^{\text {th }}$ March 2014. MRI Brain showed evidence of ill-defined T2/FLAIR hyperintense areas involving pons, medulla, middle and 


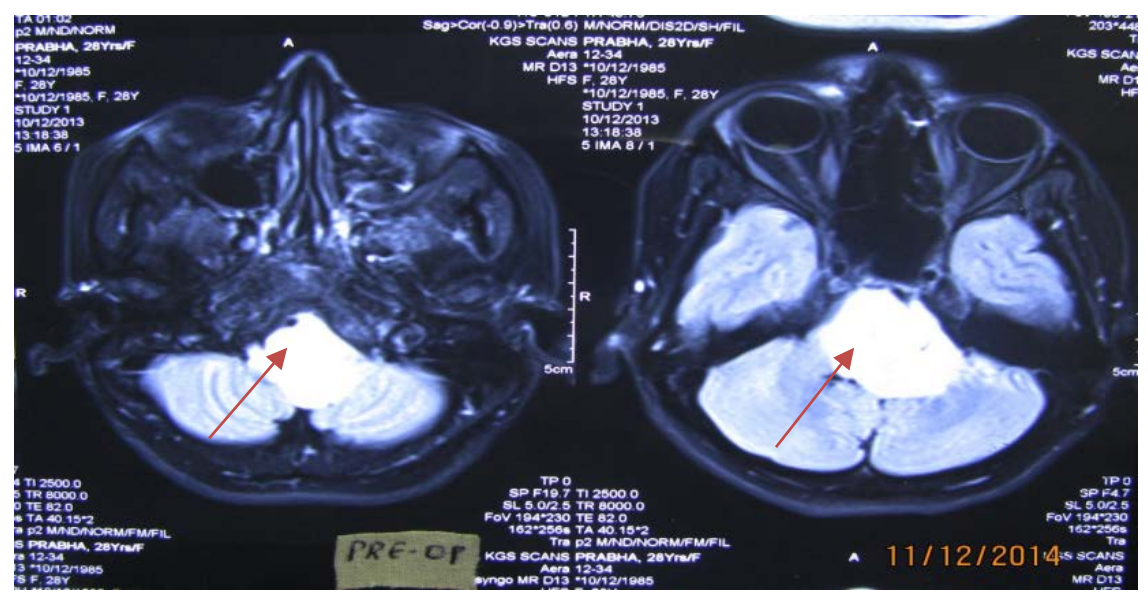

Figure 1. MRI scan done on 10/12/2013 indicates presence of lesion in the pons and medulla region of the brain stem.

inferior cerebellar peduncles. Contrast study shows two nodular enhancing lesions in the medulla, measuring about $1.1 \times 1.0 \mathrm{~cm}$ and $1.3 \times 1.0 \mathrm{~cm}$ near the left foramen of LUSKA (Figure 2). Moreover, Magnetic Resonance Spectroscopy indicated elevation in Choline and reduction in NAA.

Patient was started with chemotherapy Temozolomide (TMZ) $250 \mathrm{mg}$ once in a day for 5 days. The patient was treated with three cycles of chemotherapy; the first cycle of the chemotherapy was started on $18^{\text {th }}$ March 2014, while the second cycle on $17^{\text {th }}$ April 2014 and the third cycle of chemotherapy on $19^{\text {th }}$ May 2014. After 3 cycles of chemotherapy, on $18^{\text {th }}$ June 2014 patient complained of diplopia and right sided Hemiparesis for which antioedema measures were started and an MRI was performed on $20^{\text {th }}$ June 2014. Mild increase in a size of the lesion was observed post 3 cycles of Temozolomide chemotherapy with MRI scan (Figure 3). MRI Brain Findings was evidence of ill-defined T2/FLAIR hyperintense areas involving pons, medulla, middle and inferior cerebellar peduncles. Contrast study showed two nodular enhancing lesions in the medulla, measuring about $1.6 \times 1.0 \mathrm{~cm}$ and $1.8 \times 1.6 \mathrm{~cm}$ near the left foramen of LUSKA (Increase in size of the lesion compared to the March 2014, MRI) (Table 1).

As there was progressing disease during Temozolomide chemotherapy, the treatment plan was shifted from chemotherapy to a recombinant humanized monoclonal antibody Nimotuzumab (200 mg/week, BIOMAB ${ }^{\circ}$ ) which was given for total 8 cycles (From $28^{\text {th }}$ June 2014 to $18^{\text {th }}$ August 2014). Thereafter, the patient was assessed with MRI scan post 8 cycles of Nimotuzumab (BIOMAB ${ }^{\circ}$ ) on $25^{\text {th }}$ Aug 2014. The MRI Brain of the patient showed evidence of ill-defined T2/FLAIR hyperintense areas involving pons, medulla, middle and inferior cerebellar peduncles. Contrast study shows two nodular enhancing lesions in the medulla, measuring about $1.1 \times 1.1 \mathrm{~cm}$ and $1.6 \times 1.1 \mathrm{~cm}$ near the left foramen of LUSKA (Decrease in size of the lesion compared to the June 2014, MRI) (Figure 4).

Nimotuzumab (BIOMAB ${ }^{\circledR}$ ) was continued for additional 8 cycles of 200 $\mathrm{mg} /$ weekly scheduled from $28^{\text {th }}$ August 2014 to $17^{\text {th }}$ October 2014. After 


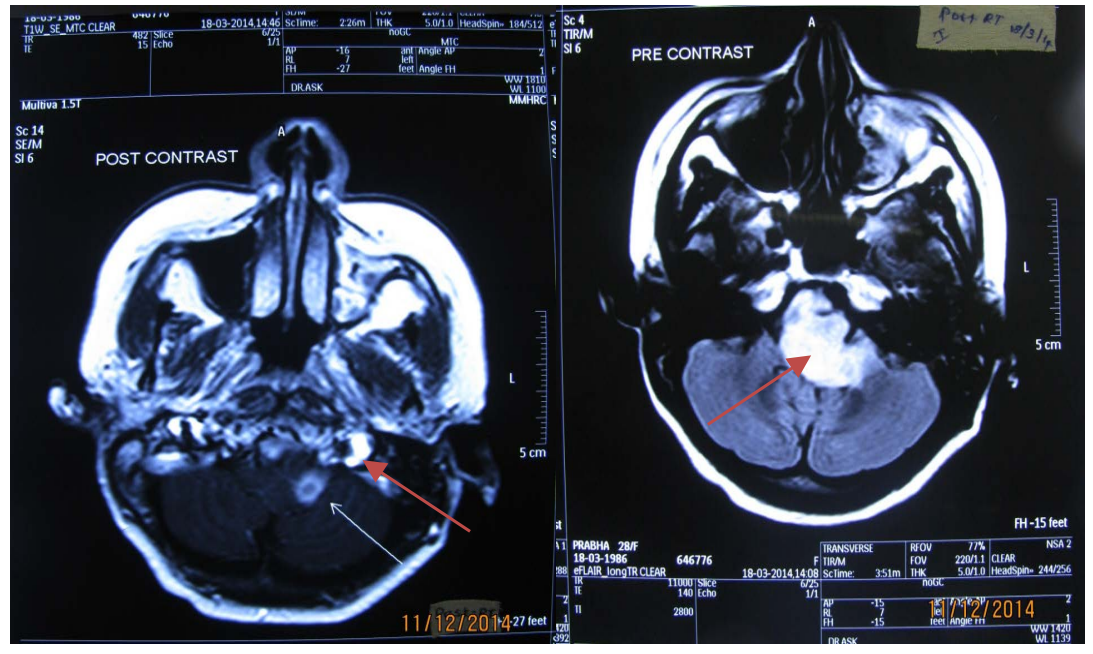

Figure 2. MRI scan done on 18/03/2014 6-week post-radiotherapy indicate no change in size of lesion.

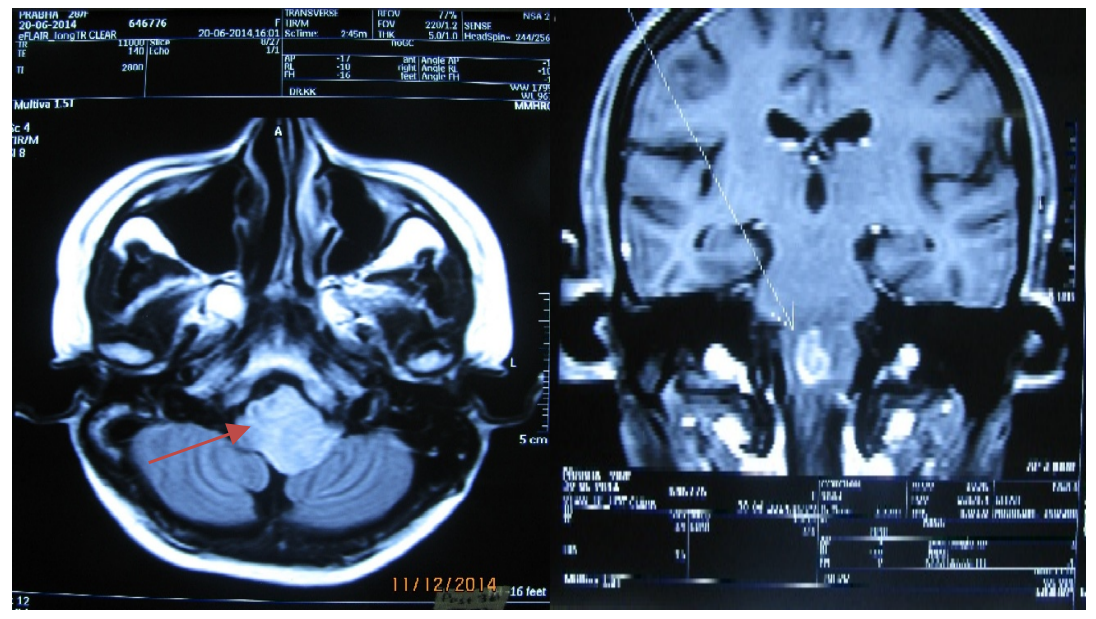

Figure 3. MRI scan of a patient on 20/06/2014 post-chemotherapy (Temozolomide) showed increase in a size of the lesion.

Table 1. Clinical presentation of patient, tumor size evaluated by contrast MRI and treatment given at various time points.

\begin{tabular}{|c|c|}
\hline Timeline & Clinical presentation, tumour size, treatment \\
\hline $\begin{array}{c}10 \text { December } \\
2013\end{array}$ & $\begin{array}{l}\text { Patient presented with progressive headache, nausea, and vomiting } \\
\text { MRI on subsequent day showed the presence of an expansile lesion in the } \\
\text { pons, medulla and cervico-medullary junction with extension into the middle } \\
\text { and inferior cerebellar peduncle on left side } 1.2 \times 1.0 \mathrm{~cm} \text { and } 1.3 \times 1.0 \mathrm{~cm} \text {. }\end{array}$ \\
\hline $\begin{array}{c}13 \text { December } \\
2013\end{array}$ & EBRT, 54 Gy in 30 fractions for 6 weeks was given \\
\hline $\begin{array}{l}18 \text { March } 2014 \\
(6 \text {-week post } \\
\text { radiotherapy) }\end{array}$ & $\begin{array}{l}\text { No clinical improvement } \\
\text { Contrast study showed two nodular enhancing lesions in the medulla, mea- } \\
\text { suring about } 1.1 \times 1.0 \mathrm{~cm} \text { and } 1.3 \times 1.0 \mathrm{~cm} \\
\text { Temozolomide } 250 \mathrm{mg} \text { once in a day for } 5 \text { days for three months }\end{array}$ \\
\hline
\end{tabular}




\section{Continued}

\begin{tabular}{cl}
\hline $\begin{array}{c}\text { May 2014 ( one } \\
\text { month after } \\
\text { completion of } \\
\text { chemotherapy) }\end{array}$ & $\begin{array}{l}\text { Worsening of clinical condition of patients with complaints of diplopia } \\
\text { and right sided Hemiparesis-anti oedema measures were started } \\
\text { Contrast MRI on subsequent day showed increased in the size of lesion } \\
\text { Nimotuzumab } 200 \mathrm{mg} \text { weekly IV was administered for } 8 \text { cycles }\end{array}$ \\
$\begin{array}{c}\text { Aug 2014 (post } 8 \\
\text { cycles of } \\
\text { nimotuzumab) }\end{array}$ & $\begin{array}{l}\text { Contrast MRI showed decrease in size of the lesion, measuring about } 1.1 \times \\
1.1 \mathrm{~cm} \text { and } 1.6 \times 1.1 \mathrm{~cm}\end{array}$ \\
$\begin{array}{c}\text { Nimotuzumab was continued for additional } 8 \text { cycles of } 200 \mathrm{mg} \text { weekly IV } \\
8 \text { cycles of }\end{array}$ & $\begin{array}{l}\text { Contrast MRI showed that tumour size was further reduced, measuring } \\
\text { about } 1.2 \times 1.0 \mathrm{~cm} \text { and } 1.0 \times 1.2 \mathrm{~cm}\end{array}$ \\
nimotuzumab) & Nimotuzumab 200 mg three weekly for $4 \mathrm{cycles}$ \\
10 February 2015 & Patient stopped treatment voluntarily \\
10 October 2015 & $\begin{array}{l}\text { Patient presented with progressive symptoms. MRI showed two new le- } \\
\text { sions with largest lesion measuring } 3 \times 3.2 \mathrm{~cm} . \text { PCV regimen, which was } \\
\text { given for } 3 \text { cycle }\end{array}$ \\
3 February 2016 & Death \\
\hline
\end{tabular}

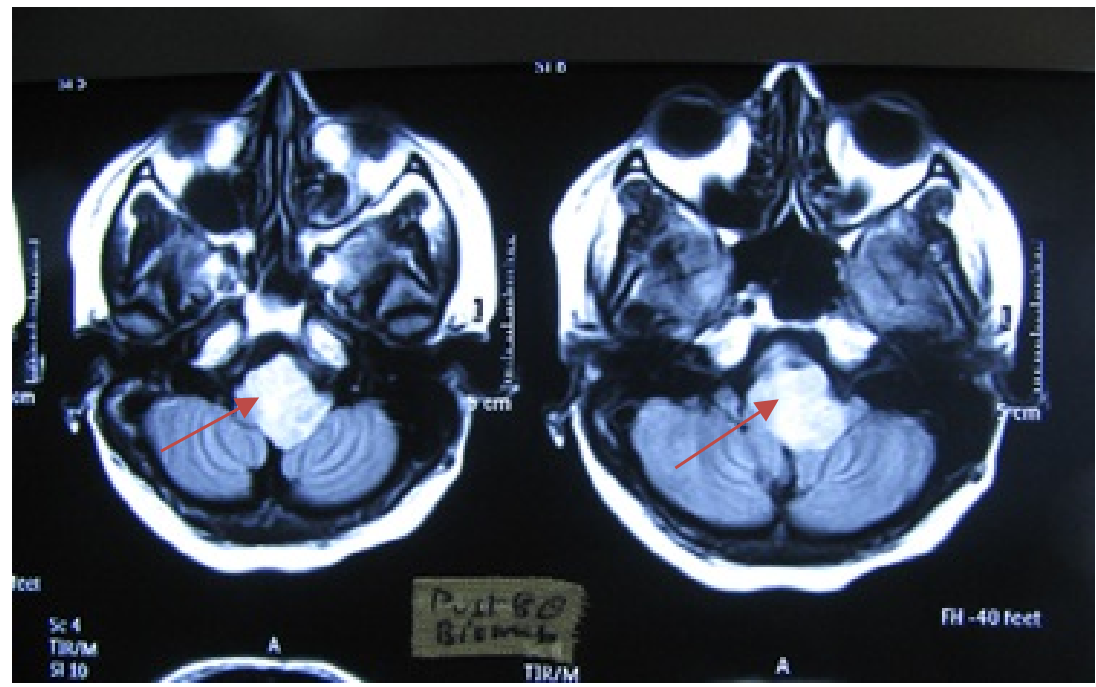

Figure 4. Post 8-cycles of Nimotuzumab treatment MRI scan done on 25/08/2014 showed reduced size of the lesion.

completion of this schedule, patient underwent for MRI scan on $2^{\text {th }}$ October 2014. The MRI Brain was showed evidence of ill-defined T2/FLAIR hyperintense areas involving pons, medulla, middle and inferior cerebellar peduncles. Contrast study shows two nodular enhancing lesions in the medulla, measuring about $1.2 \times 1.0 \mathrm{~cm}$ and $1.0 \times 1.2 \mathrm{~cm}$ near the left foramen of LUSKA (Further reduction in size of the lesion though small compared to the previous MRI) (Figure 5).

Later Nimotuzumab $\left(200 \mathrm{mg}\right.$ q3w, $\mathrm{BIOMAB}^{\circ}$ ) was continued and rescheduled as the 1st cycle of 3 weekly schedule started on 17th November 2014 and 2nd cycle on $5^{\text {th }}$ December 2014. She had completed 4 cycles on $10 / 02 / 2015$, later discontinued treatment on her own.

Patient presented on 10/10/2015 with progressive symptoms. MRI showed 


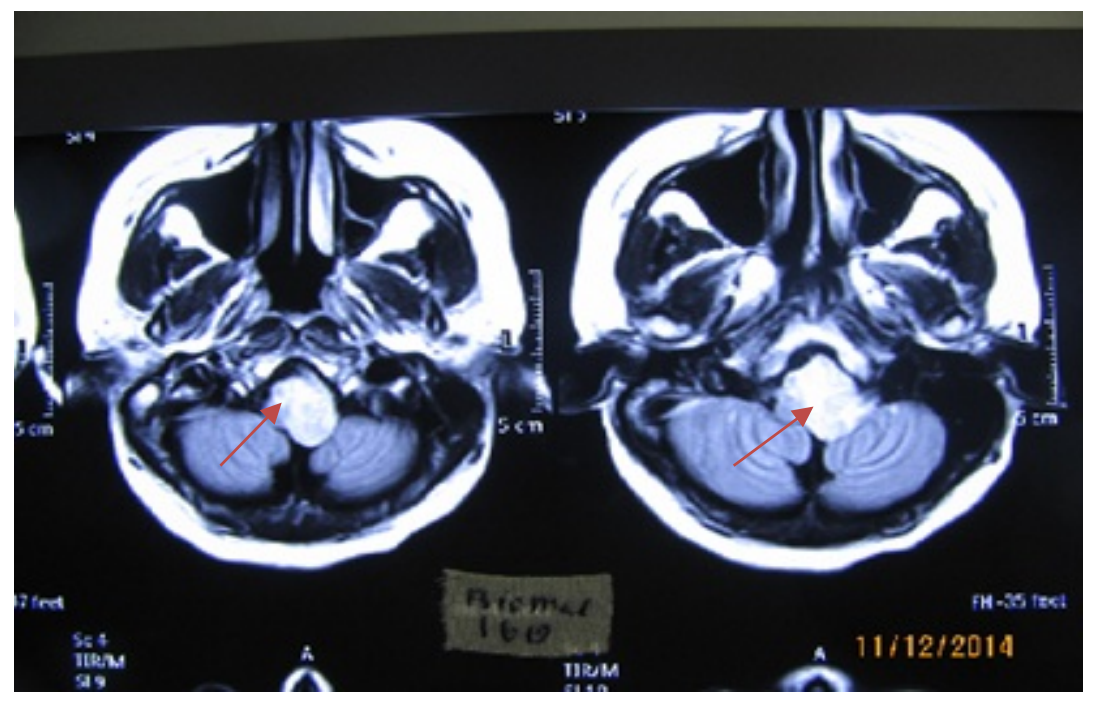

Figure 5. Post 16-cycles of Nimotuzumab treatment MRI scan done on 24/10/2014 showed further reduction in size of the lesion

two new lesions with largest lesion measuring $3 \times 3.2 \mathrm{~cm}$ with signs of carcinomatous meningitis. Patient was then started on PCV (lomustine + procarbazine + vincristine) regimen, which was given for 3 cycle and on 03/02/2016 patient succumbed to the disease.

\section{Discussion}

Gliomas of the brainstem are very infrequent in adults and mainly occur in the pons region. The tumour progresses rapidly by conquering in line structures hence the average survival of less than 1 year in children. Because of the augmented growth rate, symptoms of high-grade pontine gliomas are usually short in duration and rapidly progressive [6]. As compared to childhood brainstem glioma the average survival time in adults is as high as 5 years [1].

The first choice of treatment in brainstem gliomas is radiotherapy [1]. In this case, a 28-year-old female was diagnosed with brainstem glioma as lesion identified in pons and medulla of the brain stem. She was treated with external beam radiotherapy for 6 weeks (54 Gy in 30 fractions) but no improvement was observed in her clinical condition. Intrinsic resistance of glioma cells to damage induced by ionizing radiation could be the reason for ineffectiveness of radiotherapy [7]. The increased Cho and reduced NAA signals were assessed by MRS which is similar to results observed in a retrospective study conducted by Salmaggi et al which reported that an elevation in both Cho/NAA ratio from 1.08 to 3.32 in adult BG patients [8].

Since last decade, chemotherapy has added more attention in the treatment of glioma. TMZ showed better survival when given concurrently with radiotherapy in patients with high-grade glioma. However, survival benefits are restricted in few patients because of the ability of glioblastoma to overexpress the DNA repair protein methylguanine methyltransferase (MGMT) [9]. In our patient after treatment of TMZ (three cycles of $250 \mathrm{mg}$ once in a day for 5 days) patient pro- 
gressed with disease as seen by worsening of symptoms and increase in the size of tumour. The probable reason for lack of effectiveness to TMZ could be the presence of high MGMT activity [10].

Targeted therapies have been tried in clinical trial as many times chemotherapy and radiotherapy has not been able to improved survival of BG patients [10] [11]. EGFR overexpression is an important factor that affects the pathogenesis of high-grade glioma and observed to have a vital role in the progression of different cancers [12].

Substantial evidence supports causal role for aberrant EGFR signalling in cancer pathogenesis and resistance to radio-and chemotherapy in glioma that has made EGFR as a potential target for the therapy. Nimotuzumab is a humanized IgG1 monoclonal antibody that acts specifically as anti-EGFR. Nimotuzumab exhibits anti-cancer activity by inhibiting proliferation, survival, and angiogenesis of tumour cells. It has been approved for SCCHN in India and has proven less skin toxicity (skin rashes) than panitumumab or cetuximab [5].

In this case, significant reduction in a size of the tumour was observed after 8 cycles of Nimotuzumab (200 mg/week) treatment and drug was also found to be safe to continue for another 8 cycles. Hong et al reported that Nimotuzumab is effective in improving the response rate or the survival time when it is used with or without radiotherapy; chemotherapy in high-grade glioma [10]. In a study conducted by Solomon et al., improvement in survival rate was (Median survival time 12.4 months and 27.0 months for patients with glioblastoma multiforme and anaplastic astrocytoma respectively) observed after combining Nimotuzumab (200 mg doses of Nimotuzumab weekly for the first 6 doses) with radiotherapy (continued after every 21 days until 1 year) in 35 high-grade glioma patients when compared to a similar study conducted with radiation therapy alone exhibited mean survival time 8.0 and 12.2 months for glioblastoma multiforme and anaplastic astrocytoma patients [13].

Westphal et al. in a phase III study also assessed the efficacy of Nimotuzumab using a higher doses and found progression free survival rate (PFS) and overall survival (OS) at 12 months higher in a group of subjects treated for 12 consecutive a weekly infusions of $400 \mathrm{mg}$ of nimotuzumab during standard radiotherapy along with temozolomide followed by biweekly infusions of $400 \mathrm{mg}$ (PFS = $25.5 \%$, OS $=679$ days) than the group of subjects treated with standard radio and chemotherapy alone ( $\mathrm{PFS}=20.3 \%$, OS $=596$ days). The results were also reported remarkable for non-methylated MGMT glioblastoma [14].

These studies support that effective use of Nimotuzumab in a brainstem glioma patient has shown to delay the progression of disease and to improve the overall survival.

\section{Conclusion}

Targeted therapies have potential to reform the treatment pattern of brain stem glioma. Nimotuzumab, an anti-EGFR humanized monoclonal antibody, has improved the survival in this particular patient with aggressive brainstem glioma 
which was resistant to chemoradiotherapy. Nimotuzumab did not show any toxicity even when administered for longer duration. On the backdrop of limited effectiveness of radiotherapy and chemotherapy and encouraging results observed with nimotuzumab in present case as well as in international studies, it have made us think whether nimotuzumab should be the part of routine treatment protocol of glioma.

\section{Acknowledgements}

Authors would like to acknowledge Dr Sameer Chaudhari for drafting and editing the manuscript.

\section{References}

[1] Reyes-Botero, G., Mokhtari, K., Martin-Duverneuil, N., Delattre, J.Y. and LaigleDonadey, F. (2012) Adult Brainstem Gliomas. Oncologist, 17, 388-397. https://doi.org/10.1634/theoncologist.2011-0335

[2] Philip-Ephraim, E.E., Eyong, K.I., Williams, U.E., et al. (2012) The Role of Radiotherapy and Chemotherapy in the Treatment of Primary Adult High Grade Gliomas: Assessment of Patients for These Treatment Approaches and the Common Immediate Side Effects. ISRN Oncology, 2012, 1-6. https://doi.org/10.5402/2012/902178

[3] Zhang, J., Stevens, M.F. and Bradshaw, T.D. (2012) Temozolomide: Mechanisms of Action, Repair and Resistance. Current Molecular Pharmacology, 5, 102-114. https://doi.org/10.2174/1874467211205010102

[4] Reyes-Botero, G., Mokhtari, K., Martin-Duverneuil, N., Delattre, J.-Y. and LaigleDonadey, F. (2012) Adult Brainstem Gliomas. The Oncologist, 17, 388-397. https://doi.org/10.1634/theoncologist.2011-0335

[5] Ramakrishnan, M.S., Eswaraiah, A., Crombet, T., et al. (2009) Nimotuzumab, a Promising Therapeutic Monoclonal for Treatment of Tumors of Epithelial Origin. $m A b s, 1,41-48$. https://doi.org/10.4161/mabs.1.1.7509

[6] Lakhan, S.E. and Harle, L. (2009) Difficult Diagnosis of Brainstem Glioblastoma Multiforme in a Woman: A Case Report and Review of the Literature. Journal of Medical Case Reports, 3, 87. https://doi.org/10.1186/1752-1947-3-87

[7] Diaz-Miqueli, A. and Martinez, G.S. (2013) Nimotuzumab as a Radiosensitizing Agent in the Treatment of High Grade Glioma: Challenges and Opportunities. Onco Targets and Therapy, 6, 931-942. https://doi.org/10.2147/OTT.S33532

[8] Salmaggi, A., Fariselli, L., Milanesi, I., et al. (2008) Natural History and Management of Brainstem Gliomas in Adults: A Retrospective Italian Study. Journal of Neurology, 255, 171-177. https://doi.org/10.1007/s00415-008-0589-0

[9] Viel, T., Monfared, P., Schelhaas, S., et al. (2013) Optimizing Glioblastoma Temozolomide Chemotherapy Employing Lentiviral-Based Anti-MGMT shRNA Technology. Molecular Therapy, 21, 570-579. https://doi.org/10.1038/mt.2012.278

[10] Hong, J., Peng, Y., Liao, Y., et al. (2012) Nimotuzumab Prolongs Survival in Patients with Malignant Gliomas: A Phase I/II Clinical Study of Concomitant Radio-Chemotherapy with or without Nimotuzumab. Experimental and Therapeutic Medicine, 4, 151-157.

[11] Jose, A., Ivon, C., Ricardo, C., et al. (2015) Radiation Therapy and Nimotuzumab in Children and Adolescents with Brainstem Gliomas: A 5-Year Institutional Experience. Neuro Open Journal, 2, 45-50. https://doi.org/10.17140/NOJ-2-111 
[12] Yang, Q., Guo, C. and Chen, Z. (2015) Profile of Nimotuzumab in the Treatment of High-Grade Glioma. OncoTargets and Therapy, 8, 819-825.

[13] Solomon, M.T., Miranda, N., Jorrin, E., et al. (2014) Nimotuzumab in Combination with Radiotherapy in High Grade Glioma Patients: A Single Institution Experience. Cancer Biology \& Therapy, 15, 504-509. https://doi.org/10.4161/cbt.28021

[14] Westphal, M. and Bach, F. (2012) Final Results of a Randomized Phase III Trial of Nimotuzumab for the Treatment of Newly Diagnosed Glioblastoma in Addition to Standard Radiation and Chemotherapy with Temozolomide versus Standard Radiation and Temoziolamide. Journal of Clinical Oncology, 30.

Submit or recommend next manuscript to SCIRP and we will provide best service for you:

Accepting pre-submission inquiries through Email, Facebook, LinkedIn, Twitter, etc. A wide selection of journals (inclusive of 9 subjects, more than 200 journals) Providing 24-hour high-quality service User-friendly online submission system Fair and swift peer-review system Efficient typesetting and proofreading procedure Display of the result of downloads and visits, as well as the number of cited articles Maximum dissemination of your research work

Submit your manuscript at: http://papersubmission.scirp.org/

Or contact jct@scirp.org 